\title{
URBAN REGENERATION IN HERITAGE CONSERVATION AREAS: CULTURE AS A TOOL OF ENHANCEMENT
}

\author{
MARIA TERESA BROSETA PALANCA ${ }^{1} \&$ BLANCA PÉREZ MERINO $^{2}$ \\ ${ }^{1}$ Instituto Universitario de Restauración del Patrimonio, Universitat Politècnica de València, Spain \\ ${ }^{2}$ Ayuntamiento de Valencia (City Council of Valencia), Spain
}

\begin{abstract}
In June 2017, a seminar on urban renewal in heritage areas was celebrated by the Architecture College of the Polytechnic University of Valencia (Spain) and the General Administration of Housing Management, Refurbishment and Urban Renewal. The conference was about the analysis of the current challenge of urban renewal management of deteriorated zones that must be the object of preservation. The new points of view to undertake the discussion are based on the Historical Urban Landscape figure and the renew intervention tools proposed by the 36th Meeting of UNESCO General Conference, where public participation, knowledge and planning tools and normative and financial resources were presented, as well as the continuous concern of improving the quality of life in historical districts. During the conference several management experiences were explained by civil servants, professionals, and professors; new criteria and methodologies' evolution could be taught in such a way that have been the origin of new research that intends to put the focus on municipal management mechanisms. The evaluation of a series of successful experiences serves as a guideline to illustrate, list and classify the various instruments that the local authorities have at their disposal, resulting in a vast catalogue of feasible resources that have already been tested. Meanwhile, all this information is compared with what is being done in the city of Valencia, to easily recognize the weaknesses that the city has in terms of diffusion, promotion and enhancement of its vast heritage and therefore being able to design a series of objectives and future lines of work intended to reverse this situation. The research is being developed in five areas: municipal administrative structure, urban renewal and urban planning, economic incentives, awareness and dissemination and outer resources target. The study is in progress, and provisional results are obtained linked to the economic fields of individuals' incentives and target of private resources.
\end{abstract}

Keywords: heritage preservation, urban renewal, housing refurbishment, historical districts, municipal management.

\section{INTRODUCTION}

The need of preservation of old quarters' is totally accepted in occidental culture, supported by the European Charter of Historical Heritage, which has been an efficient base of preservation planning from 1970s. However, Raffaele Panella's demands are more valid now than ever, 23 years since his speech during the Seminar on Intervention Strategies in Historical Districts, held in Valencia in 1993, where he claimed [1]:

“... the historical districts' preservation is a pending matter, despite the cultural progress and, mainly, despite the general agreement in preservation. Meanwhile degradation goes on because of poorness in some areas of national territory; Furthermore, in contrast to the past, degradation is due to the excessive overburden in some important districts because of the role of centrality in their respective metropolitan systems. Indeed, degradation and destruction are also consequence of new phenomenon, like overburden of tourist activities incompatible with buildings and environment fragility. [...]

The difficulty is to exceed the pure protection, the pure norm by architecture and urban culture - prohibition with general goals, without immediate transfer to technical 
actions of evident content -hence, those who use and produce the refurbishment lack an adequate theory and technique of intervention".

The new points of view to undertake the discussion, are based on the Historical Urban Landscape and the renew interventions tools proposed by the 36th Meeting of UNESCO General Conference, the 11th November 2011, where public participation, knowledge and planning tools, firstly, and secondly, normative and financial resources, are present, as well as the continuous worry to improve the quality of life in historical districts.

The present paper is firstly aimed at the analysis of the heritage areas management in some of the main Spanish cities, regarding preservation rules, planning tools and good practices for the implementation of refurbishment and reuse strategies. In comparison to these contents, the paper evaluates the conditions of the regional administration in the Autonomous Community of Valencia, and preliminary commandments of regional power are suggested as imperative for the heritage enhancement.

Thereon and additionally, the assessment goes down to municipalities' competencies regarding architecture heritage management. The paper has a second objective: to assess the level of development in Valencia City Council addressing heritage enhancement by means subsidizing policies for heritage owners and private companies economic support, two of the five areas included in the whole research in progress. After the assessment the first suggestions for improvement are made, focused on obtaining the required conditions for the heritage enhancement.

\section{BACKGROUNDS}

\subsection{European framework of urban protection}

Since the mid-20th century the criteria for historical districts' renewal have added new requirements that make the tasks and goals by administration and professionals more complex each time. This criteria progress is gathered hereunder, where the guiding European and international conventions on urban heritage retrofit are collected (Table 1).

\subsection{Juridical framework of preservation and factual reality}

Rules about cultural heritage and urbanism form a broad and detailed compilation sometimes cut off from current situation, and therefore of low efficacy.

The legal framework defines the preservation tools (catalogues and plans) in detail from 1998, and nearly 20 years later, these tools are still not written in the most of cases.

If the rhythm of planning production in our region continues (the average of master plans' approval is 7 years) in the next decade (2016-2026) more than the 58\% of Valencian towns (the most with population under 5,000 inhabitants) will carry on without a catalogue of protection and will have master plans approved from 1985 to 1998, with urban norms formulated in non-conservationist ages, far away from heritage preservation theories [2].

Basic norms for old quarters' preservation are still not implemented, although they are more easily set up than catalogues and heritage plans; specifically, the old quarter delimitation, the preservation of the urban structure and building typologies, the binding relationship between the economical profit and the plot where the heritage building rises, and that between demolition and new constructions license, as well as other measures to promote the empty sites construction. 


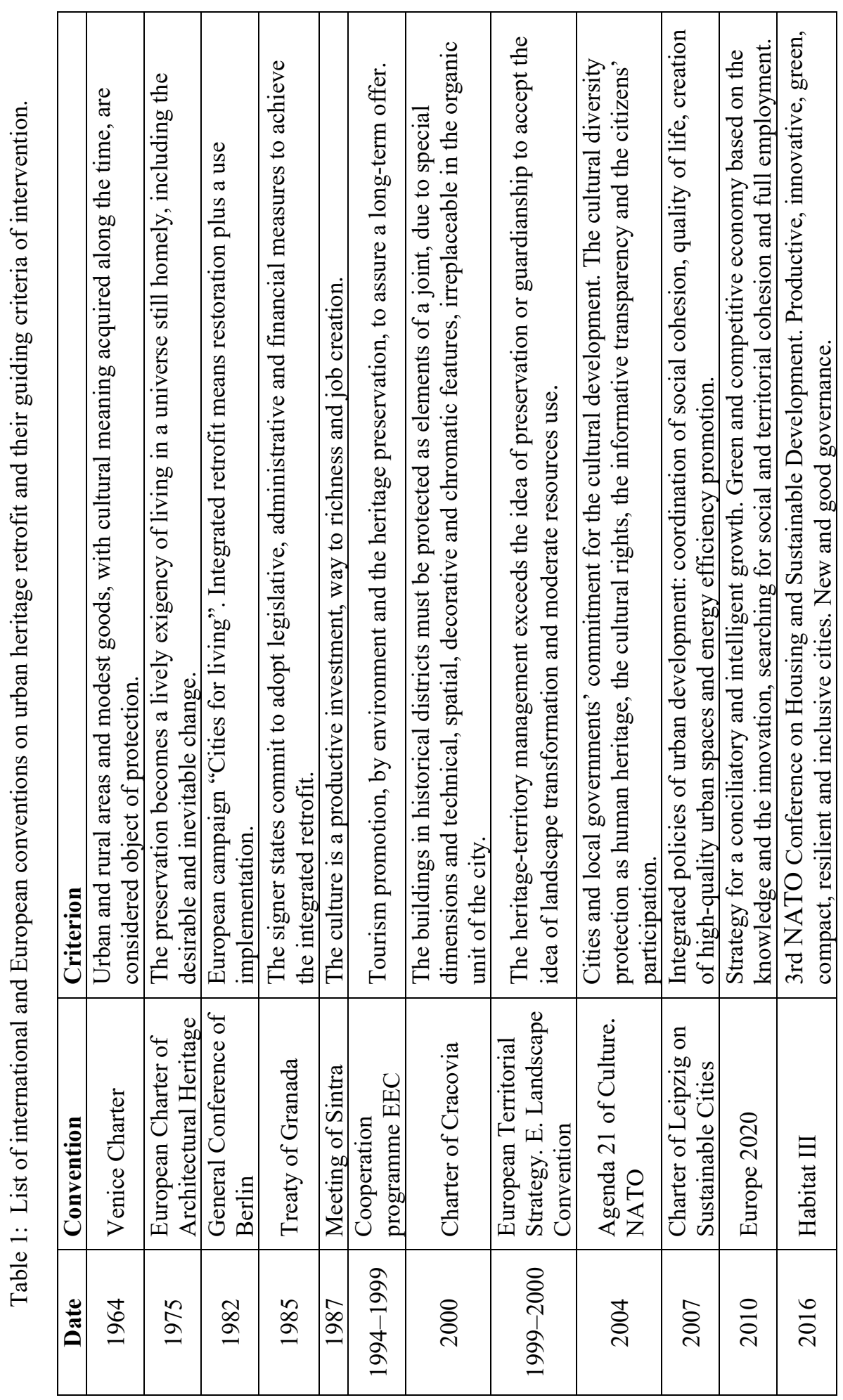


The especial plans for the protection of historical districts and monuments' surroundings require the durable commitment of city councils' politicians, due to their complexity and long proceedings, than exceed the ability of most of local administrations; consequently, only three special plans of protection have been approved in small villages and eleven in bigger towns over 452 townships in Valencian Community.

After preservation and planning issue, highly improvable, management and intervention could reach better results if some measures were not overlooked; for instance, the register of empty sites and buildings to refurbish and the report of buildings' assessment, mandatory for those older than 50 years.

In conclusion, the said before summarized the current matter status of the issue regarding legal framework: the administration incompetence to apply efficiently the norms related to heritage.

\subsection{Current administrative measures for the urban regeneration}

The urban renewal and building refurbishment have been a punctual practice where the preservation of singular monuments has prevailed over integral policy of social and functional character, being the private investment an unresolved matter. However, Law 8/2013, 26th June 2013, about Refurbishment, Regeneration and Renewal, is the legal framework which is expected to reach deeper aims, like the following:

- To improve the estate of preservation and the energy efficiency in existing buildings through the building assessment report.

- To guarantee the universal accessibility and to avoid disabled discrimination.

- To accelerate and make flexible the urban renewal process by the legislation amendments (Land Law, Condominium Law, Building Law and Technical Code of Building).

- To establish new tools for investment and cooperation between public and private agents (Plans for the Refurbishment Promotion and Housing Plans).

- To implement new measures for the urban renewal management, like the Isolated Proceedings for Buildings Refurbishment, in place of owner or with owner's cooperation.

These last tools, protected under orders of enforcement over heritage buildings, have still not given a boost to restoration. The orders of enforcement, which become high investments for landlords, are finally unaccomplished and the council, afterwards, may choose between the subsidiary execution and the open tender to select the refurbishment developer. In the case the tender is declared void because of the lack of profitability, then, the Local Council is obliged to undertake the first option of subsidiary execution. Facing this foreseen administrative proceeding, some Councils, lately deprived of funds, only issue orders of enforcement in case of extreme deterioration of buildings due to breach of safety, reported by third parties' complains.

\section{SUCCESSFUL REFURBISHMENT INTERVENTIONS}

The contributions to the conference were illustrative, with broad practical contents about three main subjects, presented below, which have been demonstrated as the three axis of the good management of urban heritage. 


\subsection{The handbooks of refurbishment as a tool of historical districts preservation}

The restoration handbook is a guide of all the techniques and elements of the vernacular architecture in the region. This teaching guide is useful to promote the popular architecture retrofit: the values and constructive techniques of traditional housing are listed and explained, as well as the aesthetic norms to follow, with positive and negative examples, related to the current special plan of protection.

Although the handbook has not a mandatory character, it is a consulting tool that orients professionals and landlords about construction and building maintenance according to the architectural tradition in the zone.

Some handbooks' authors highlighted the danger linked to the practice of facades preservation, since in many cases, under an apparent newly-made façade, unknown ancient buildings stay unprotected.

\subsection{Management and intervention in historic districts}

The historical districts renewal management transcends the mere building protection; the task needs an integrated strategy to implement diverse and simultaneous ways of action related to four big issues: Environment, Culture, Architecture and Collaborative Management.

Environment: The homely urban landscape characteristic of the historical centres must be preserved through the activation and reuse of the public space with sustainable and kind proposals of social character, thought for all kind of people: families, children, elder people, disabled. The pedestrian mobility must be planned with safety routes and traffic-calm zones of $20 \mathrm{~km} / \mathrm{h}$ or $30 \mathrm{~km} / \mathrm{h}$ areas. In addition, searching for the population growth in these zones, third sector activities must be promoted, by means the subsidized rental or purchasing.

Culture: the cultural resources of the historical city can be promoted by routes or cultural tours, interpretation centres, museums and open space remodelling. The identity and the citizens' awareness recovery will bring with activities of history and culture dissemination, taking examples from the arts and crafts, traditional festivities, fairs, historical celebrities in the village, etc.

Architecture: Aids for housing refurbishment must be preceded by the identification of the most representative samples of vernacular architecture and the protection including them in the catalogue, as well as the public dissemination by the handbook of refurbishment.

Collaborative management: Open access to information and public participation, always inspired in transparency and good governance criteria, must be present in the first stages of pilot projects' planning, which should provide success indicators of the complete renewal plans.

\subsection{The demonstration of good practices in historic districts management}

The cultural tourism promotion as stimulating factor, not only for local economy but for education and raising awareness, was always the objective of the Toledo Consortium [3] when started the city centre retrofit in 2001 . The action was supported by the city Strategic Plan, which guaranteed the performances' continuity despite the political changes, as was explained by Soledad Sánchez-Chiquito, the current executive heritage manager of the Consortium. Several strategies of tourism exploitation are developed in relation with the retrofit of the historical district of Toledo; to illustrate, the agreements between Consortium and individuals allow the visits of historical private houses (included in the Consortium's 

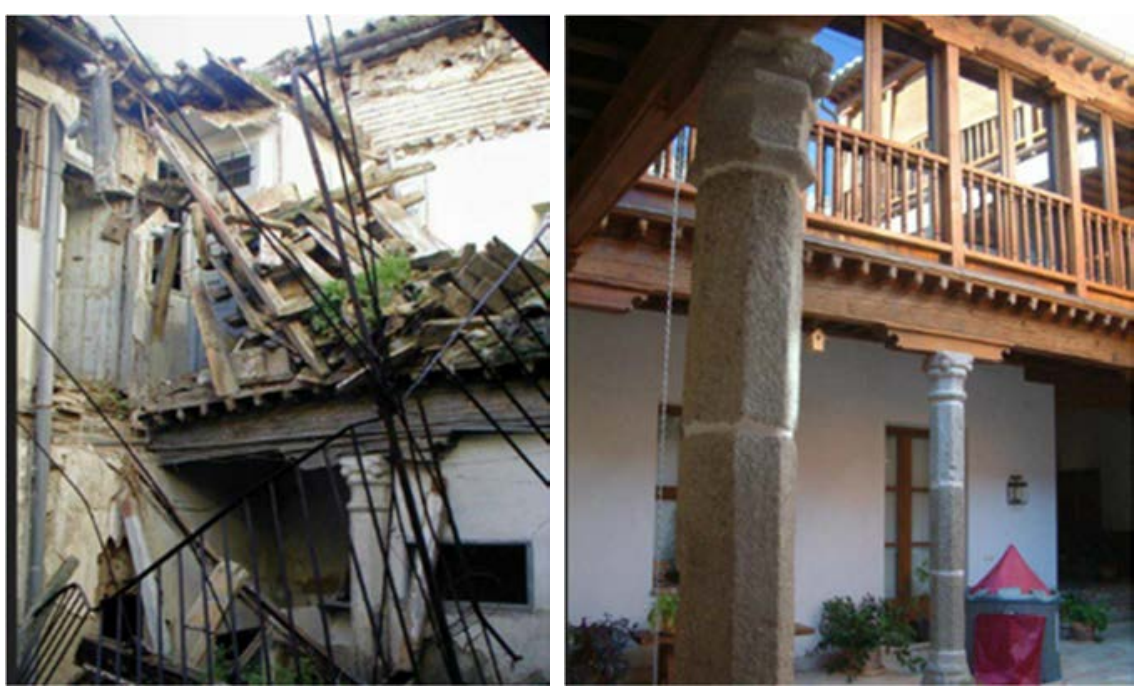

Figure 1: Housing refurbishment by Consortium of Toledo [3].

programme "unknown heritage tours") in exchange for the subsidized refurbishment or the complete payment of the works (Fig. 1).

The restoration of the Old Cathedral of Saint Mary of Vitoria and its urban surrounding was possible due to the programme "open for repairs" [4]; a historical, social and economic high-impact project, where a derelict cathedral became a generating resource of benefits in all the historical area, up to the point of Álava institutions were earning more than they invested, as it was pointed by Gonzalo Arroita, the last manager of the historical district renewal office.

The goal of sustainability was the self-financing, considering in addition of the economical heritage profitability, other of social, urban, cultural and touristic kind, returning public investments to citizen in different ways. Around the cathedral, the historical district is renewed not only by the housing refurbishment but also by means the projects of accessibility improvement, of hotel sector qualification, of public equipment implementation and cultural activities development (Fig. 2).

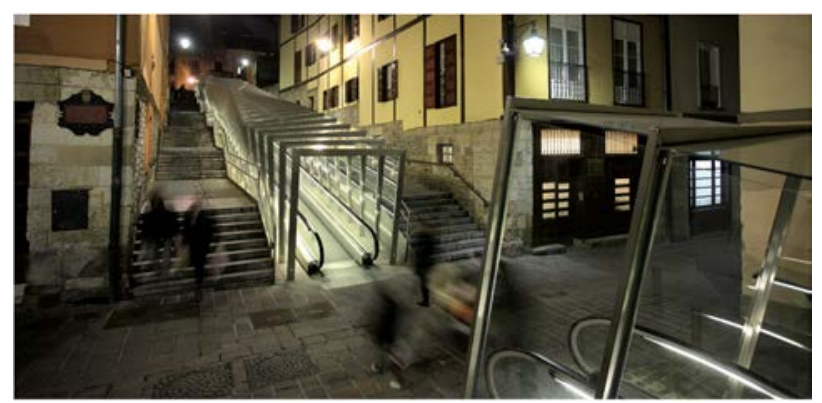

Figure 2: Project to improve the accessibility in the Historical District of Vitoria (Basque Country) [4]. 
The citizen participation was tried to be incorporated in all the mentioned projects, but without the complete accomplishment of goals, since the participatory processes require slow proceedings than even can stop the projects; due to this fact the direct actions are needed to make the most of the favourable refurbishment situation. The consensus and the unanimous political agreement for a long period allowed the renewal performances without obstacles, only directed by technical criteria; however, actions do not happen so fluently currently due to political confrontation.

Another interesting presentation was in charge of the architect Sebastià Jornet about the urban renewal projected in PinCAT (Fig. 3), like the Development of Urban Improvements in San Jaume neighbourhood from the Special Protection Plan for Historical District of Tortosa (2005).
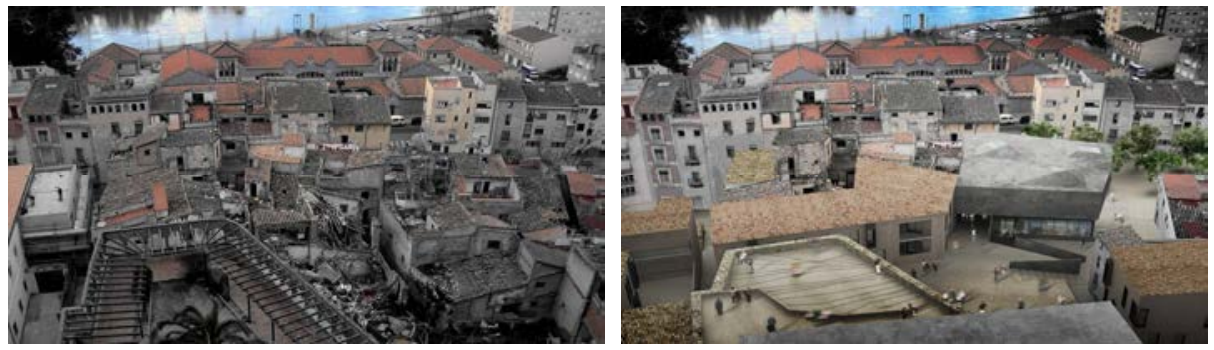

Figure 3: Development of urban improvements in San Jaume neighbourhood of Tortosa $[5]$.

\section{URBAN REGENERATION PROMOTION}

\subsection{Economic incentives for citizens}

The activity of subsidized housing retrofit is competency of State and Regions; therefore, it is out of municipal competency, which only voluntarily, issues economic programmes destined to building refurbishment in urban regeneration areas.

The ordinances that rule the subsidy may be conceived as a management tool of enhancement, from the point of view of the intervention criteria control, beyond the economic grant. Administration can monitor the interventions and guaranty the building values preservation linked to the positive action of the aid.

Fig. 4 is obtained from the study of the rules for subsidized retrofit around Spain; the research focuses in the level of protection of buildings to get the grant and the formulas used to enhance and control the heritage preservation.

Among the Spanish subsidies studied, the particular cases of Barcelona and Madrid offer the highest levels of dissemination and resources.

In Barcelona the grants by the Housing Consortium [6], with regional and municipal investment, allow a big number of granted cases per year. These campaigns seek to ensure the social protection of tenants and exclude the tourist houses. Besides, the Local Institute of Urban Landscape and Life Quality stablishes three technic support lines in 2019: refurbishment in buildings, retail and extraordinary works.

In Madrid from 2016, in the framework of the Strategic Plan of Urban Regeneration (MAD-RE) [7] promoted by the Sustainable Development Area, the municipality launches the grants for the housing improvement linked to the nineteen Regeneration Areas of the city. 


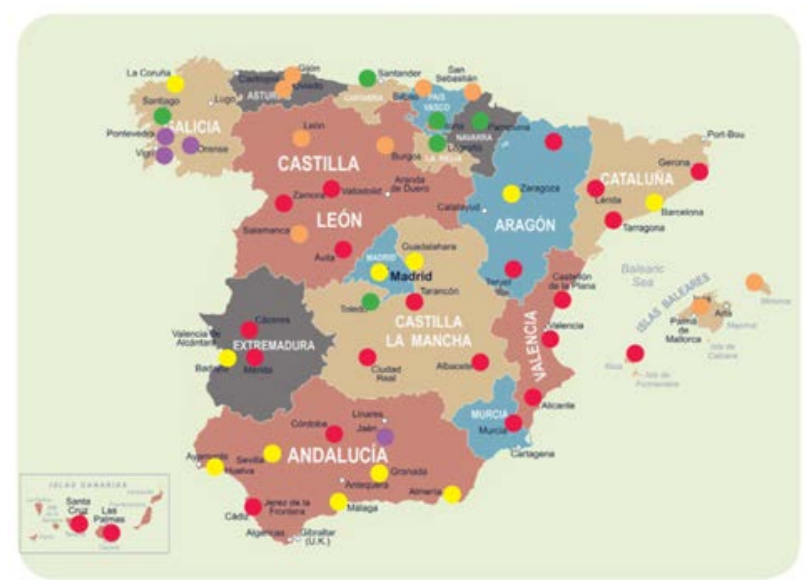

Figure 4: Study of the rules for subsidized refurbishment. Green: Call focused on heritage preservation; Yellow: Call with grants to listed buildings; Orange: Recurrent call without considering listed buildings; Purple: Municipal campaigns with state and regional funding; Red: No call of aids. (Source: Authors.)

In order to summarize, the requirements and instruments obtained from the economic programmes studied are gathered below:

- Mandatory intervention criteria given by subsidy rules or by a refurbishment handbook written and annexed to the economic programme, which should contain materials and traditional technics of construction, with special mention to handmade arts and crafts for restoration.

- Manage without demolition works, as well as those of inner emptying or typologies alteration. The grants will increase in case of integral refurbishment. Mandatory recovery of heritage materials as inner woodwork, blacksmith's craft, cement tiles, plasterwork, etc.

- The future intended use after the restoration must be usual and permanent homes for a minimum period, as owner or landlord (a precise term of contract can be considered or rental prices control). In congested zones, the tourist uses are forbidden.

- Aids to housing self-promotion in empty sites and penalties in case of purchasing the following years after receiving the grant.

- Creation of a register of expert companies in restoration and bonus for the use of them.

- Get rid of the discordant elements with the heritage value of the building: antennas, air-conditioners, wiring and advertisements.

- Mandatory Technic Survey of old building. Proposal of green energies and ecofriendly materials. Bonus for the housing improvement related to quality of life, structural safety and acoustic isolation.

- Enhancement of traditional retail and art and crafts workshops.

- Mandatory previous control inspection to assess the interventions.

- Period of building maintenance in which the control surveys and visits to disseminate the results are mandatory. 
- Promotion of temporary use transfer to municipality or cultural activities implementation.

Thus, with the implementation of all the mentioned factors or some of them, based on the particular needs of each zone or the specific values to protect, two objectives are reached: firstly, compensations to the extraordinary loads of listed buildings and secondly, other objective of social kind that help us to mould the heritage city we wish.

\subsection{Urban management for the regeneration}

The city councils are competent in planning regulations with the arrangement of management areas were the economic profit for owners is measured and controlled by administration.

The urban profit transfer is a legal tool, applicable in urban land out of management areas, which allows to balance the actual profit of a plot and owner's rights of profit [8].

Consequently, the owner of a listed building, who suffers the economic profit freeze by comparison with the designated by planning, can be compensated by means the purchase of the profit difference. This management needs the existence of opposite situations [9].

The origin of this tool comes from the American law, when in 1968, under the name of Transferable Development Rights (TDR), was used in order to preserve the Grand Central Station of New York. Lately, it was useful to rescue several theatres in Broadway and some singular buildings, like the Old Slipe Police Station or historic housing areas like Amsterdam Yard.

In a simple way, this urban concept is based on protecting the rights that owners of listed buildings (Landmarks) have to sell their unused profit to other plots, not necessarily located in the same area, in exchange for maintaining the protected building. The profit differences in New York City are especially cumbersome, since the number of levels to reach extremely exceeds the height of listed buildings, making the TDR quite suitable.

Spanish Land Law has included this technic to transfer economic resources in developable land to urban areas, so that, it would be possible to use the profit surplus in developable sectors to agree the urban areas regeneration by means administrative contracts [10]. Then, buildings retrofit could come from the higher buildable areas in other scope.

The viability of these operations needs the delimitation of distribution areas and the use of special coefficients of correction [11].

Regarding the first term, the discontinuous distribution areas must incorporate together zones to refurbish with more dynamic zones, in order to transfer profit from first to second ones. Otherwise, there could be continuous distribution areas with different historic buildings, where the profit transfer would be in cash. Besides, the coefficients of value correction should balance the bigger charges of catalogued buildings.

\subsection{Private companies support}

Both, sponsorship and patronage consist in an economic contribution as a communication strategy of the private sector, in search of social and cultural prominence for the company or its owner. The sponsorship is a marketing strategy, comparable with advertising by traditional means, television and newspapers. However, the patronage is known as an investment with results in the medium and long term, not only based on donations for a determined work, but to heritage dissemination and promotion activities.

In Spain companies patronage is far from the range of other countries with more philanthropic tradition, like English-speaking countries in case of personal donations (in the USA $80 \%$ of incomes are from individuals, not from companies). 
The temporary use transfer and management of heritage buildings is a good way of cooperation chosen by the Portuguese Government, (Agreement of Economy, Culture and Treasury Departments), which has recently launched a programme of architecture heritage open to private investment for the tourist development, called REVIVE.

Administration transfers the management of empty public buildings with high cultural value by means a public tender that make them useful for new economic activities in the field of hotel and restaurant business, cultural activities and other forms of leisure and retail, in exchange for the refurbishment, enhancement and dissemination.

The programme, which counts on municipalities' collaboration, aims at the promotion of regional destinations, keeping the public property (generally the exploitation is for 50 years), the guaranty of heritage preservation and the more suitable exploitation for the region by the tender conditions [12].

Non-profit entities are formed by one or more natural person or legal entities, who allocate part of their goods to a clear purpose of general interest. The first law about foundations was approved in 1994 and stablished exemption in taxes for companies which participate in activities of general interest (patronage). The organism which leads the foundation is called board and normally is formed by founders. The foundations' audit is State and Regional Government competency.

Foundations in Netherlands are limited liability companies, which it means that the partners' responsibility is limited to the invested capital. Then, in case of incurring into debt, partners do not response with their personal capital. The limited liability is attractive for architecture heritage preservation, because the creditors cannot ask the stockholders to compensate any debt. Therefore, interested people can collaborate to get a social aim without any financial risk.

Take, as an example, the company Amsterdam Monumenten Fonds NV, in Netherlands, that was founded in 1992 for restoring 19th century monuments, like churches or retail not adaptable to housing.

In 1999 many of the stockholders of Stadsherstel Amstel, the first company for the city restoring (1956), also became stockholders of Amsterdam Monumenten Fonds NV, after the two companies merged. As a result of this event Stadsherstel Amsterdam NV currently restores all kind of threaten monuments, not only houses.

Together with City Council, the main Dutch banks and assurance companies are stockholders, willing to win less in exchange for social and cultural programmes that provide a good opinion.

Stadsherstel Amsterdam NV has achieved the synthesis of a public limited company for profit and an institution for social interests by means the state-private collaboration, which is possible with a maximum annual dividend of 5\%. In case of dissolution the stockholders only receive their outlay plus the dividend. The surplus of funds is assigned to social housing or monuments restoring [13].

\section{CONCLUSIONS}

After the conference of 2017 some conclusions were given by the organizing committee by way of Decalogue of main suggestions to improve the management of protection and urban renewal of historical districts:

1. To promote the dissemination and the social awareness of heritage knowledge and appreciation, therefore, it becomes an incentive in economic and social sectors. To disseminate the good examples and practices in preservation and refurbishment, including digitalization, regarding typologies and constructive techniques. 
2. To increase the administration support in researching and assessment tools promotion, like GIS cartography and digital data base to identify, locate and assess the heritage. To implement ICT to heritage, including open access public registers.

3. To review the regional norms regarding listed buildings reconstruction and historical fabrics restructure, opposite to international conventions of preservation and restoration.

4. To improve the heritage guardianship of regional administration, which must act in a collaborative and proactive way with city councils, shortening deadlines and proceeding more efficiently.

5. To strengthen the figure of the catalogue by means of cooperation between administrations when economical and technical resources are not enough.

6. To correct the figure of the special plan of protection as a tool with social an economical profitability, in company with the convenient management of proposals. A plan without investment programme will not be developed. The pilot projects linked to a plan might be a good practice to gather indicators of the plan success.

7. To integrate the public participation process from the first stages of planning, joining the social agents in the proposals phase.

8. To extend the protection criteria to strategic, territorial and local planning, taking into account the environmental and landscape values of heritage.

9. To consider the implementation on a small scale of strategies of integrated sustainable urban development and offices of urban renewal, spread to the most of townships, further than State or European investment goals

10. To attend to the singular requests of small villages with simple management tools from the point of view of heritage preservation and urban planning.

As a complement of the Decalogue, and after the first steps of the research about municipal management mechanisms, having analysed economic incentives, urban management tools and experiences of private sector collaboration, a series of objectives and future lines of work are design meaning to reverse this situation of the city of Valencia:

The agreements more feasible with the private sector are the public contracts for the transfer of the building use. The example of use transfer held in Portugal would unblock the situation of many municipal properties, which are closed and deteriorated, or even closed after the refurbishment.

This is the case of the municipal farmhouses of La Torre, Falco and those in the streets Beato Gaspar Bono and Olba, which are declared Local Outstanding Buildings. Their enhancement is one of the objectives of the municipal planning for the Protected Scope of the Orchard of Valencia, where some attractive activities are proposed for the private sector like tourist accommodation, restaurants or schools.

The use transfer contracts are the more suitable procedure to add the reuse and maintenance of the building to the refurbishment, mixing public and private interests. Thus, a list of municipal buildings subject to the private investment can gather the optimal use possibilities for both, administration and companies, once the buildings destined to public services and those not appropriated are rejected.

Besides the farmhouses, more singular historic buildings are waiting to be restored with no plans to reuse, like the old ceramic factory "Ceramo", the American Casino, the Water House or the Harbour Shed. All of them could become singular landmarks after a good management, with the inclusion of mixed cultural, social and leisure activities, which generate public and private joint effort. 
An association for the heritage enhancement is a good proposal for Valencia City. In Valencia, many public and private partners can collaborate and be leaded by the Municipality, for undertaking activities for the architecture heritage promotion (routes, diffusion webs, school campaigns, conferences organization).

This kind of association would centralise documentation and information and unique agreed guidelines, as well as promote the restoration handbooks as reference for the technic assessment and the good training for expert professional in architecture heritage.

The tasks of dissemination, enhancement and specialised training should count on the Universities collaboration, Architecture and Fine Arts Schools in Polytechnic University as much as the Art History School in Valencia University, with the development of R\&D programmes.

Other proposals would be the creation of an honourable mention for the outstanding heritage practices, the promotion of contracts for young experts in heritage and the updated register of heritage building companies and craftsman with accredited experience in refurbishment.

\section{REFERENCES}

[1] Panella, R., Estrategias de intervención en centros históricos, Official College of Architects of Valencian Community, Valencia, 1993. (In Spanish.)

[2] Broseta Palanca, M.T., Registro, catalogación y planificación del patrimonio urbano arquitectónico: Una aproximación al caso valenciano, Polytechnic University of Valencia, Valencia, 2014. (In Spanish.)

[3] The Consortium of Toledo, http://consorciotoledo.com/mcomunicacion/index.asp. (In Spanish.)

[4] Open for Repairs, guided tours at the Cathedral of Saint Mary of Vitoria (Álava, Basque Country). www.vitoria-gasteiz.org.

[5] Jornet Llop Pastor Arquitectes, Modificación Puntual del POUM de Tortosa en el barrio de Sant Jaume, 2010. http://jlp.cat/es/content/modificaci\%C3\%B3n-puntualdel-poum-de-tortosa-en-el-barrio-de-sant-jaume-0. (In Spanish.)

[6] Ayudas del Consorcio de Vivienda del Ajuntament de Barcelona, https://habitatge.barcelona/ca. (In Catalan.)

[7] Plan Estratégico Madrid-Recupera, https://planmadre.madrid.es/. (In Spanish.)

[8] Hurtado, F., La reforma de las ciudades, las transferencias urbanísticas, los excedentes de aprovechamiento en El agente rehabilitador. Notas sobre gestión en suelo urbano consolidado. Navarra: Aranzadi, 2005. (In Spanish.)

[9] García, M.J., La conservación de los inmuebles históricos a través de técnicas urbanísticas y rehabilitadoras, Aranzadi, Elcano, 2000. (In Spanish.)

[10] González-Varas, S., La rehabilitación urbanística, Aranzadi, Pamplona, 1998. (In Spanish.)

[11] Fariña Tojo, J., La protección del patrimonio urbano. Instrumentos normativos, Akal, Madrid, 2000. (In Spanish.)

[12] https://revive.turismodeportugal.pt/.

[13] Pickard, R., Funding the Architectural Heritage: A Guide to Policies and Examples. Council of Europe Publishing: Strasbourg, 2009. 